\title{
Self-repairing mechanism and surface characterization of compressor vanes lubricated with oil added with magnesium silicate hydroxide nanorods
}

\author{
Libo Wang ${ }^{1}$, Yi Yang ${ }^{1}$, Yi Qin ${ }^{2}$, Gang Yang ${ }^{1}$, Yuan Qin ${ }^{1}$, and Mingxia Wu ${ }^{1, *}$ \\ ${ }^{1}$ School of Mechanical Engineering, Sichuan University, Chengdu, 610065, PR China \\ 2 Design, Manufacture \& Engineering Management, University of Strathclyde, Scotland, UK
}

Received: 1 April 2019 / Accepted: 23 October 2019

\begin{abstract}
Using magnesium silicate hydroxide as additive of lubricating oils for reducing friction in engineering equipment/machinery has been researched intensively. However, some mechanism relating to the growth of the self-repairing layers on the won surfaces is still not clearly explained. At the same time, using magnesium silicate hydroxide (MSH) in the form of nanorods showed great promise in reducing friction and wear. In this study, surface-modified MSH in the form of nanorods was used as additive of polyolester oil (POE) which was then used for the lubrication of compressor vanes. The sample parts were studied on the morphology and the microstructure of the self-repairing layer in a great depth. The results showed that self-repairing layers with different thicknesses were generated on the worn surfaces when the POE with 1 wt.\% nanorods-MSH was used. It was found that the self-repairing layers consist of organic-inorganic composite membranes, and with increase of working time of the compressor vanes, the self-repairing layers become denser and thicker, while their microstructural form remains to be similar. The situ-repairing capability of the metal surfaces (roller-vane pair of the compressor) enforced by the MSH nanorods is very significant, indicating high potential for industrial applications where boundary and mixed lubrications are needed.
\end{abstract}

Keywords: Magnesium silicate hydroxide (MSH) / nanorods / polyolester oil / self-repairing / compressor vane

\section{Introduction}

Ultrafine serpentine powders have gained increasing interest as reactive media stimulating self-repairing of Fe-based metal surfaces subjected to friction [1-5]. However, natural serpentines are defective as they contain impurity elements such as, $\mathrm{Fe}, \mathrm{Ni}$ and $\mathrm{Al}$, which could influence self-repairing reactions unpredictably. To deal with this problem, pure synthetic magnesium silicate hydroxide (MSH) has become the constituent of most currently used serpentine powders [6-9]. At the same time, performance of the nanorods of MSH with good crystallinity that can be produced by hydration has been studied in recent year, in surface rubbing situations. It was focused mainly on friction reduction behavior. Its anti-wear performance has, however, not been thoroughly investigated [10-13].

Line-contact friction pairs exist in many types of precision machinery, an example being the roller-vane pairs in air conditioning compressors. Vane wear is a severe

\footnotetext{
* e-mail: wumingxia@scu.edu.cn
}

problem that directly affects compressor efficiency and significantly determines time to failure. Compressor vanes often work in oil at temperatures ranging from 0 to $110^{\circ} \mathrm{C}$ and are subjected to alternating stresses of $0-345 \mathrm{MPa}$. Failure criteria of a vane is often referred to wear, e.g. 3.0 $\mu \mathrm{m}$ wear after $500 \mathrm{~h}$ continuous work. Therefore, level of the wear is an important indicator for judging the vane's performance [14-17].

Previously, significant research had been undertaken with a view to decrease the wear in compressor vanes. Long researched compressor vanes with DLC coatings found the wear can be greatly reduced with such coatings [18]. Chen undertook research on nitrided surfaces and found that both surface hardness and wear resistance are greatly improved [19]. Lee et al. used TiN coating to prolong wear life of the compressor vane and found that this could improve the reliability of the compressor [20]. Until now, nitriding is a traditional method often used for strengthening the surface of the vane. Since the mass-scale synthesis of MSH nanorods has been realized and the manufacturing cost has been lowered, using MSH nanorods as a self-repairing additive to POE oil has become reality [21-25]. 

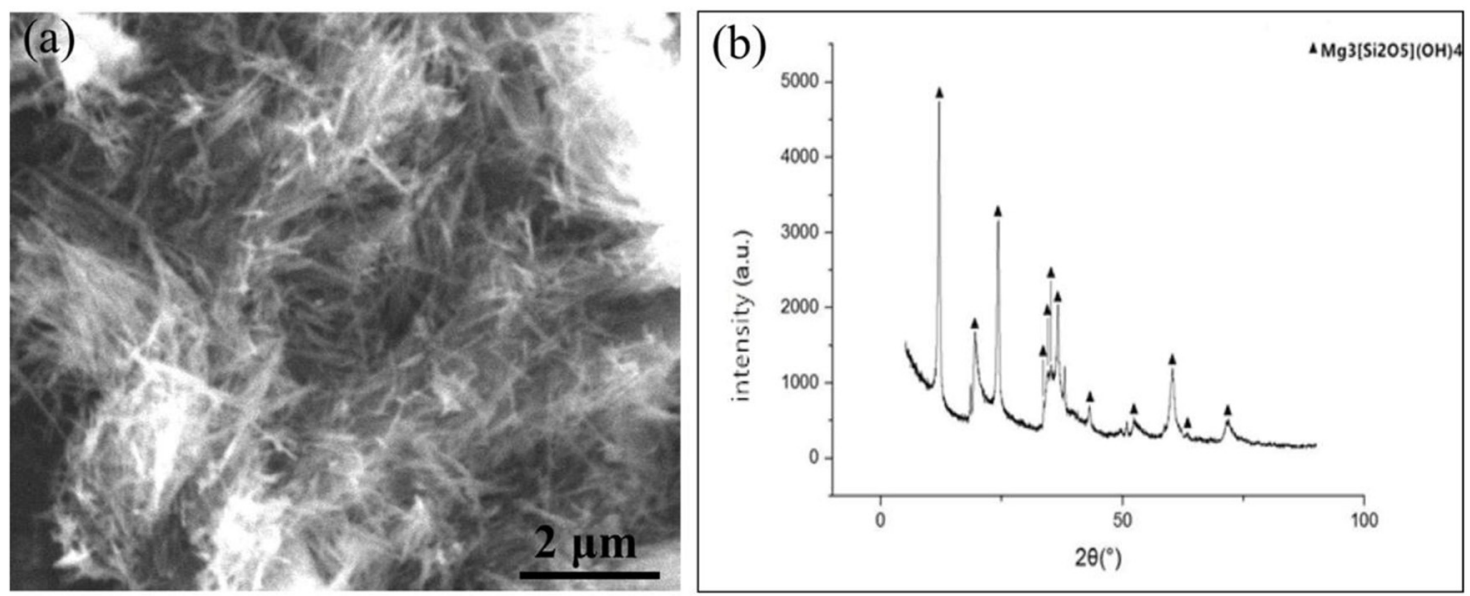

Fig. 1. (a). SEM image of MSH nanorods and (b) XRD of MSH nanorods.
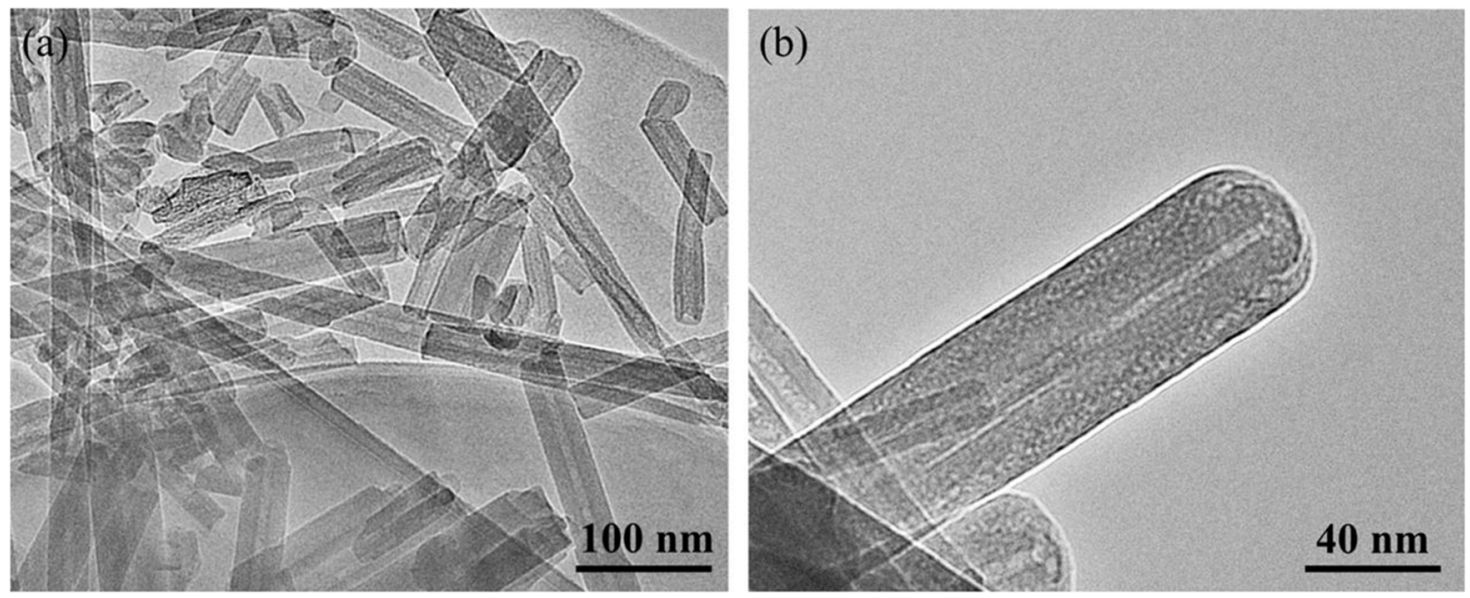

Fig. 2. TEM images of surface-modified MSH nanorods.

In the work described in this article, MSH nanorods were added to POE oil and the formation of the selfrepairing layers under rubbing friction was investigated. The dynamic formation of self-repairing films and wear conditions were monitored and the mechanism of selfrepairing layer formation was analyzed. The results provide a basis for theoretical modelling and for promoting more extensive industrial utilization of MSH nanorods containing oils used for combating wear in machinery and general engineering devices/equipment.

\section{Test apparatus, material and experimental procedure}

\subsection{Nanorods and oil sample preparation}

The MSH nanorods were synthesized by a hydrothermal synthesis process. The specific method is as follows: firstly, mixing $\mathrm{MgO}$ with $\mathrm{Na}_{2} \mathrm{SiO}_{3}$ in a molar ratio of 3:2 into distilled water, and then, adjusting the $\mathrm{pH}$ of the mixture to 13 with $\mathrm{NaOH}$ titration solution. The solution was then placed in an autoclave for reaction with a pressure of about 7.0 MPa. The reaction took place at $280^{\circ} \mathrm{C}$ for $48 \mathrm{~h}$. After the reaction was completed, the mixture was washed with distilled water until neutral, and finally, it was dried with a dryer at about $100^{\circ} \mathrm{C}$ for $12 \mathrm{~h}$. After being dried, as shown in Figure 1a, the product was an aggregate of nanorods. The morphology of the synthesized product is shown in Figure 1a. Results of XRD analysis (Fig. 1b) showed that the nanorods are pure MSH and they have good crystallinity. To obtain good dispersity in the oil, the MSH nanorods were mixed with $1 \mathrm{wt} . \%$ oleic acid in a planetary ball-mill at $400 \mathrm{rpm}$ for $24 \mathrm{~h}$ to obtain nanorods (Fig. 2). As can be seen from Figure 2, the inner diameter of the nanotubes is $5-10 \mathrm{~nm}$ and the outer diameter is about $30-40 \mathrm{~nm}$. The surface-modified MSH nanorods have good dispersity. Finally, ultrasonic dispersion (power $200 \mathrm{~W}$, temperature $50^{\circ} \mathrm{C}$, duration $60 \mathrm{~min}$ ) was used to further ensure uniform dispersion in the POE oil.

\subsection{Experiment}

The relative motion of roller-vane friction pairing in the compressor is shown in Figure 3. In order to simulate real working conditions of a vane, a testing apparatus was built (shown in Fig. 4). The apparatus enabled two steel-vanes to be held against a rotating roller in an environment with nanorods-additive containing oil. Firstly, the surfacemodified MSH nanorods were dispersed in the POE with a 

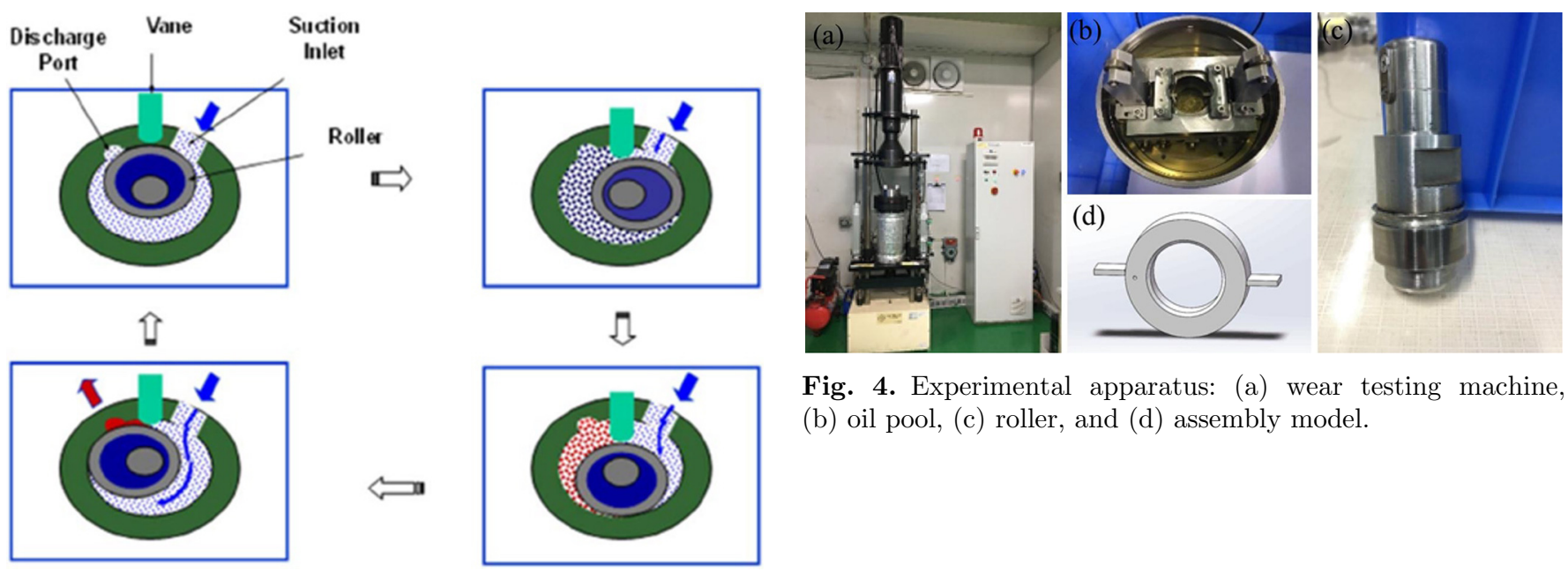

Fig. 4. Experimental apparatus: (a) wear testing machine, (b) oil pool, (c) roller, and (d) assembly model.

Fig. 3. Relative motion of roller-vane friction pairs.

Table 1. Experimental parameters.

\begin{tabular}{lllllll}
\hline No. & $\begin{array}{l}\text { Speed } \\
(\text { Revs } / \mathrm{min})\end{array}$ & $\begin{array}{l}\text { Temperature } \\
\left({ }^{\circ} \mathrm{C}\right)\end{array}$ & $\begin{array}{l}\text { Loading } \\
(\mathrm{N})\end{array}$ & $\begin{array}{l}\text { Contact pressure } \\
(\mathrm{MPa})\end{array}$ & $\begin{array}{l}\text { Time } \\
(\mathrm{h})\end{array}$ & $\begin{array}{l}\text { Concentration } \\
(\text { wt.\% })\end{array}$ \\
\hline $\mathrm{A}$ & 1100 & 110 & 160 & 345 & 18 & 1 \\
$\mathrm{~B}$ & 1100 & 110 & 160 & 345 & 69 & 1 \\
\hline
\end{tabular}

concentration of $1 \mathrm{wt} . \%$. The oil pool was then evacuated and the refrigerant RA410 (HFC) inserted, until the pressure reached $4.15 \mathrm{MPa}$. The oil was heated to $110^{\circ} \mathrm{C}$ and the temperature automatically adjusted to around $110^{\circ} \mathrm{C}$ during the whole experiment. Two vanes of untreated $11 \mathrm{Cr} 17$ steel with hardness $700 \mathrm{HV}$ were positioned in diametric opposition against the side of the roller, which was made with cast iron with hardness HRC 47-57. The experimental parameters are given in Table 1. On expiration of the experimental time the vanes were cleaned with alcohol.

\subsection{Characterization and analysis}

Each vane was cut into 5 equal lengths along its bearing surface for examination of element distribution on the substrate and the self-repairing layer for each sample length. Topography, both 2D and 3D, of the self-repairing layers was evaluated and micro-roughness of the selfrepairing layers was calculated. For simplicity, vanes A and $\mathrm{B}$ are designated $\mathrm{A}$ and $\mathrm{B}$ for the $18 \mathrm{~h}$ and $69 \mathrm{~h}$ test, respectively.

The topography and chemical composition of the friction surfaces were obtained using SM-7500-F SEM and XRD-7000, respectively. The Raman spectrum of the developed self-repairing layers was further examined using a HORIBA XploRA PLUS Raman spectrometer, and morphology and composition further checked using an OLYMPUS GX51 metallographic microscope and X 'Pert Pro MPD X-ray with a spectrometer (EDS) diffractometer, respectively. In addition, Vickers Hardness was measured using HVS - 1000 digital display instrument and AFM analysis was used to present the micro-topography.

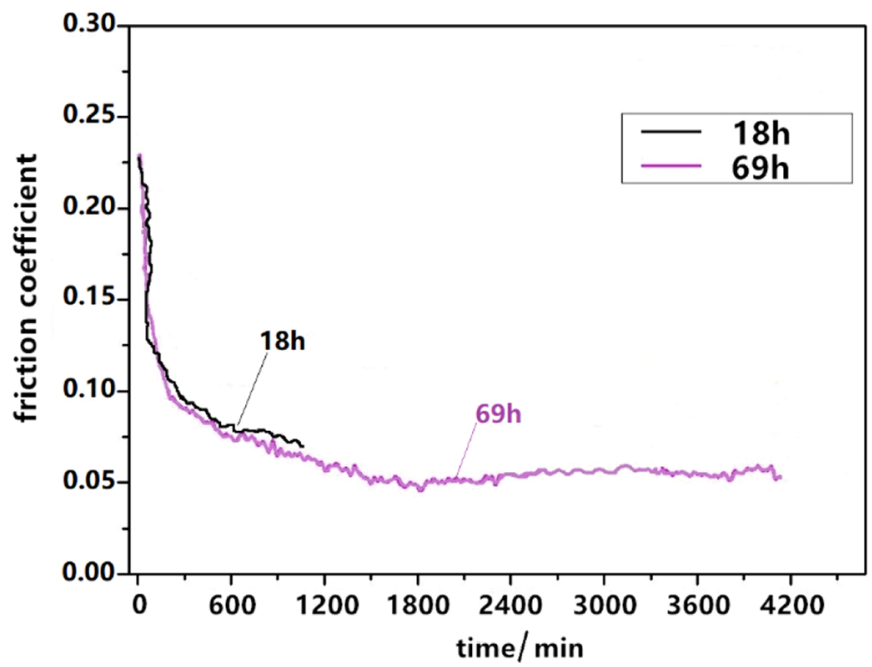

Fig. 5. Friction coefficient for tests A and B.

\section{Results and discussion}

\subsection{Coefficient of friction}

Figure 5 shows how the friction coefficient varies with testing time for two experiments. Because of being similar in work conditions, two curves are virtually similar, up to the test time of $18 \mathrm{~h}$. The coefficient begins at a value of about 0.225 and then sharply declines to a value of about 0.10 during the first $60 \mathrm{~min}$. Then the coefficient reduces more gradually to a value of about 0.075 after $18 \mathrm{~h}$ 
(1080 min) testing. Beyond the $18 \mathrm{~h}$ testing time the coefficient of the vane $B$ reduces to a value of about 0.07 at $30 \mathrm{~h}$ (1800 $\mathrm{min})$ test time and with a slight fluctuation, remains at a value of about 0.075 or less for the remainder of the test.

It is deduced that by prolonging the rubbing time, the coefficient of friction has a declining trend, but the coefficient has a fluctuation in small range towards the end. It is deduced that in the first hour the coefficient sharply decreased from 0.225 to 0.10 for the running-in of the rubbing interface, and fluctuated in a small range throughout the experiment. The friction between the vaneroller is boundary friction and the coefficient of friction is determined by a combination of the fluid friction and the solid friction. The solid friction is greatly influenced by the wear rate and the formation of self-repairing layers. Therefore, the coefficient exhibits a slight fluctuation until the dynamic balance between the wear and new-film formation has been achieved.

\subsection{Morphology of vanes}

Figure 6 shows the morphology of the worn surface of the two vanes. The width of the worn surface of vane $A$ is about $427 \mu \mathrm{m}$, and there is much corrosive pitting in the friction surface. The width of the worn surface on vane B is about $330 \mu \mathrm{m}$. The characteristics of the worn surfaces change from one side of the vane to another. The friction surface was divided into two zones, shown in two different colors: the left side of the worn surface is black and the right bright. It seems that some special substance has been laid on the worn surface and there are fewer corrosive pitting points. Since the vane suffers from elastic deformation during the experiment, thermodynamic conditions are different in the left side and the right side of the worn surface, which influences the formation of the self-repairing layers. This is probably why the morphology of the worn surface of B looks different due to the formation of selfrepairing layers locally. In the experiment, left side of the surface first contacted with the roller, then the right side. The large area of the self-repairing layers in the right side of the worn surface of B may be a result of good preservation of the layers due to the relatively mild tribological condition. However, the boundary of $\mathrm{A}$ is more distinct than that of $\mathrm{B}$.

The EDS result showed that the characteristic elements $\mathrm{Mg}$ and Si are contained in the bright region of A (Fig. 7). Since Si may come from the substrate, the presence of the $\mathrm{Mg}$ element indicates physical absorption or chemical reaction between $\mathrm{MSH}$ and the substrate.

When MSH nanorods were brought into the friction surface through the oil, they were firstly adsorbed onto the friction surface. Then, under the high pressure and high temperature, the MSH nanorods experienced intraformational sliding as well as a phase change. Products from the phase change were sintered on the surface, mixed with the $\mathrm{Fe}$ and $\mathrm{Fe}_{2} \mathrm{O}_{3}$. The transition region is a region of the mixed substrate and self-repairing layer. At first, the regions are distinct, as for A; with the extension of time, a region of the friction surface becomes covered by the self-repairing layer.

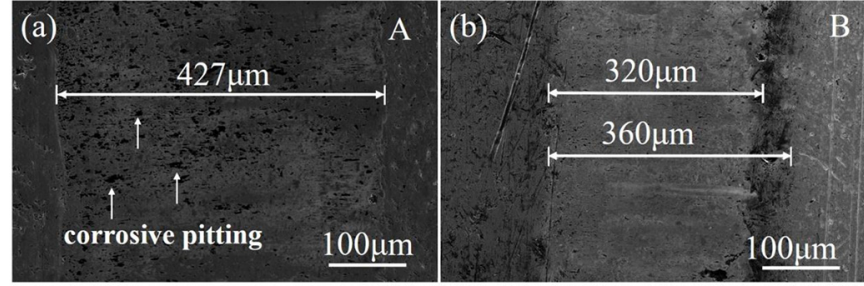

Fig. 6. Image of the worn surface of samples A and B.

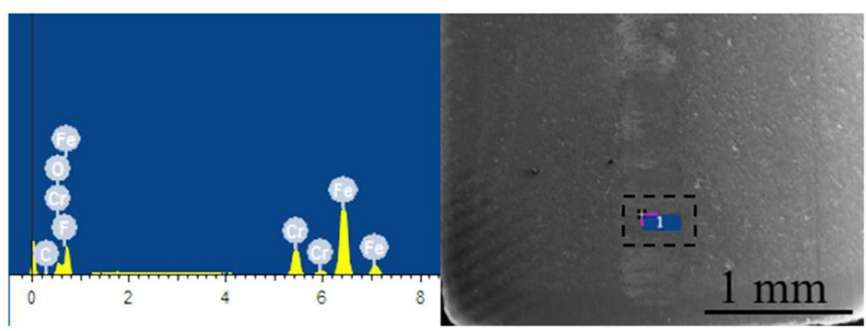

Fig. 7. EDS result for vane A.

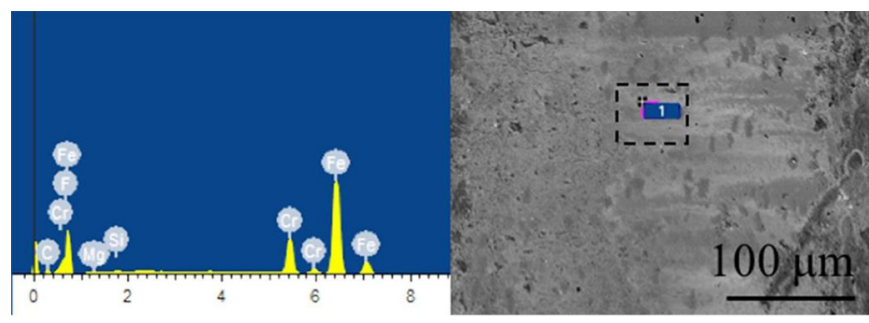

Fig. 8. EDS result for vane B.

The partial covering is manifested by the transition line and two regions on the friction surfaces. The substrate partly covered by the self-repairing layer constituted the transition region on the worn surface of $\mathrm{A}$.

Figure 8 shows the EDS result for $\mathrm{B}$ and the point is randomly selected in the friction surface. Since the RA410 is constituted by HFC, despite the element F, the other elements indicate that this is the substrate with carbonenriched layer. The concentration of $\mathrm{C}$ is higher than that in the substrate, and it is deduced that the $\mathrm{C}$ is partly from the pyrolysis of the lubricating oil. The Mg element was also found on the surface.

It is deduced that with the extension of time, more selfrepairing layers are generated on the friction surface of $B$ but they are not continuous. This phenomenon indicates that under severe working conditions (high temperature, high pressure, line contact), a balance of film-growing and wear is not easy to obtain, and the continuous self-repairing layer is difficult to achieve.

After experiments the vanes were cleaned, dried and weighed on an electronic balance of $0.1 \mathrm{mg}$ accuracy. Each vane was weighed 5 times and the results averaged (Tab. 2).

It is clear that after the experiment vane B was heavier than before and vane A decreased its weight. It seems that the self-repairing layers were generated on vane B, and that 
although vane A may have some self-repairing layers but their weight was less than the weight of the worn away metal.

\subsection{Self-repairing layer}

\subsubsection{Microstructure of vane A}

In order to observe the self-repairing layers from the crosssection, vane A was cut uniformly into 5 segments along axial direction of the rubbing surface (Fig. 9a). After polishing, grinding and corrosion of the cross-section the self-repairing layers were observed through a SEM. For the samples 1-4, morphologies of cross sections are mostly like what seen from the Figure 9b: there are no selfrepairing layers observed from the cross-section of these samples. Only sample 5, as shown in Figure 9c, has a thin layer of about $900 \mathrm{~nm}$ laid on the friction surface. The layer is continuous and the boundary between the substrate and the layer is not clear. The red line indicates the approximate boundary of the layer, which is not a straight line and follows the contour of the substrate. However, surface of the layer is relatively flat. The morphology indicates that the self-repairing layer is an in situ-layer, and it automatically adapts to the micromorphology of the substrate. There is no visible crack existing.

Analysis of element distribution is carried out by SEMEDS. Figure 10 indicates that from the layer to the substrate, C elements decline sharply. Enriched carbon layers are less than $500 \mathrm{~nm}$, which indicates the selfrepairing layer has an organic - inorganic composite layer structure. In its surface a thin, enriched carbon layer was generated due to the pyrolysis of lubricating oil. The $\mathrm{O}$ element gradually reduced with distance from the layer to substrate where it remained constant. Relating to the result for the Fe element, it is deduced that the self-

Table 2. Mass change of A and B.

\begin{tabular}{lll}
\hline $\begin{array}{l}\text { Before the } \\
\text { experiment } \\
\text { unworn vane }(\mathrm{g})\end{array}$ & $\begin{array}{l}\text { After the } \\
\text { experiment } \\
\text { Vane A }(\mathrm{g})\end{array}$ & $\begin{array}{l}\text { After the } \\
\text { experiment } \\
\text { Vane B }(\mathrm{g})\end{array}$ \\
\hline 5.3790 & 5.3643 & 5.3905 \\
5.3745 & 5.3655 & 5.3899 \\
5.3763 & 5.3647 & 5.3873 \\
5.3771 & 5.3652 & 5.3901 \\
5.3761 & 5.3681 & 5.3872 \\
Average $=5.3766$ & Average $=5.3656$ & Average $=5.3890$ \\
\hline
\end{tabular}

repairing layers contain iron oxide. When the phase change of MSH occurs, the high-active $\mathrm{O}$ produced by the fracture of the hydroxyl will greatly promote iron oxidation, thus, iron oxide participates in the composition of the selfrepairing layer. Regarding the characteristic element $\mathrm{Mg}$, coming from the MSH, its content was very small, and therefore, only information concerning the change trend of Mg could be obtained (Fig. 10c). Many of the previous research found no $\mathrm{Mg}$ in the self-repairing layers [22-25]. When MSH changes phase, part of the transition products participate in the construction of the self-repairing layer. However, some content is small and it is hard to be detected.

Although vane A loses overall weight, it still has selfrepairing layers on the worn surface. The amount of the newly grown layer-materials is, however, not sufficient for compensating for the loss due to wear. The phase change of the MSH was a key factor influencing the generation of the self-repairing layers [26,27].

\subsubsection{Microstructure of vane B}

Figure 11 shows image of a self-repairing layer viewed from the cross-section of vane $B$ and the line element distribution of the cross-section. Compared with Figure $9 \mathrm{c}$, it is clear that the self-repairing layer generated on the friction surface is thicker. It also has flat surface and its boundary with the substrate is clear. Figure 11 also shows an EDS result, and the element type and change trend are similar to that shown in Figure 9b. These results indicate that with prolonged time, the self-repairing layer becomes denser and thicker, but the composition of the layer material remains the same.

Figure 12 shows the boundary of the working surface and the non-working surface in cross-section. It is clear that the self-repairing layer is only generated on the working surface and its growth depends on the thermodynamic conditions of the friction interface. Therefore, the selfrepairing process is in-situ growth of the layer.

\subsubsection{Raman analysis}

The substrate and the self-repairing layer were analyzed by Raman spectrometry. The wave length was $532 \mathrm{~nm}$, and the Raman displacement $\Delta v$ was between 500 and $2000 \mathrm{~cm}^{-1}$. Figure 13 a shows the result for the substrates of vanes $\mathrm{A}$ and $\mathrm{B}$. The peak corresponds to $1363 \mathrm{~cm}^{-1}$ (D-bond) near the peak of diamond $\left(1332 \mathrm{~cm}^{-1}\right)$, and it is a symbol of the Sp3 bond. Meanwhile, the peak corresponds to $1590 \mathrm{~cm}^{-1}$ and $1573 \mathrm{~cm}^{-1}$ (close to $1580 \mathrm{~cm}^{-1}$, "g-bond") corresponds to the Sp2 bond, which is graphite carbon.

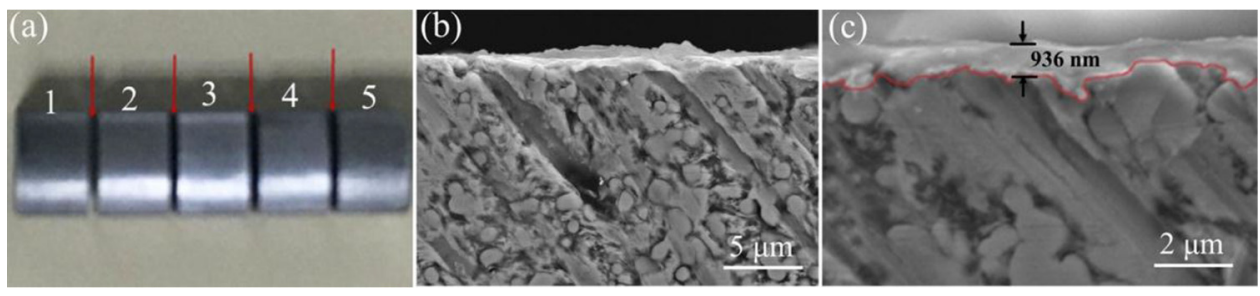

Fig. 9. Images of the cross-sections of vane A. 


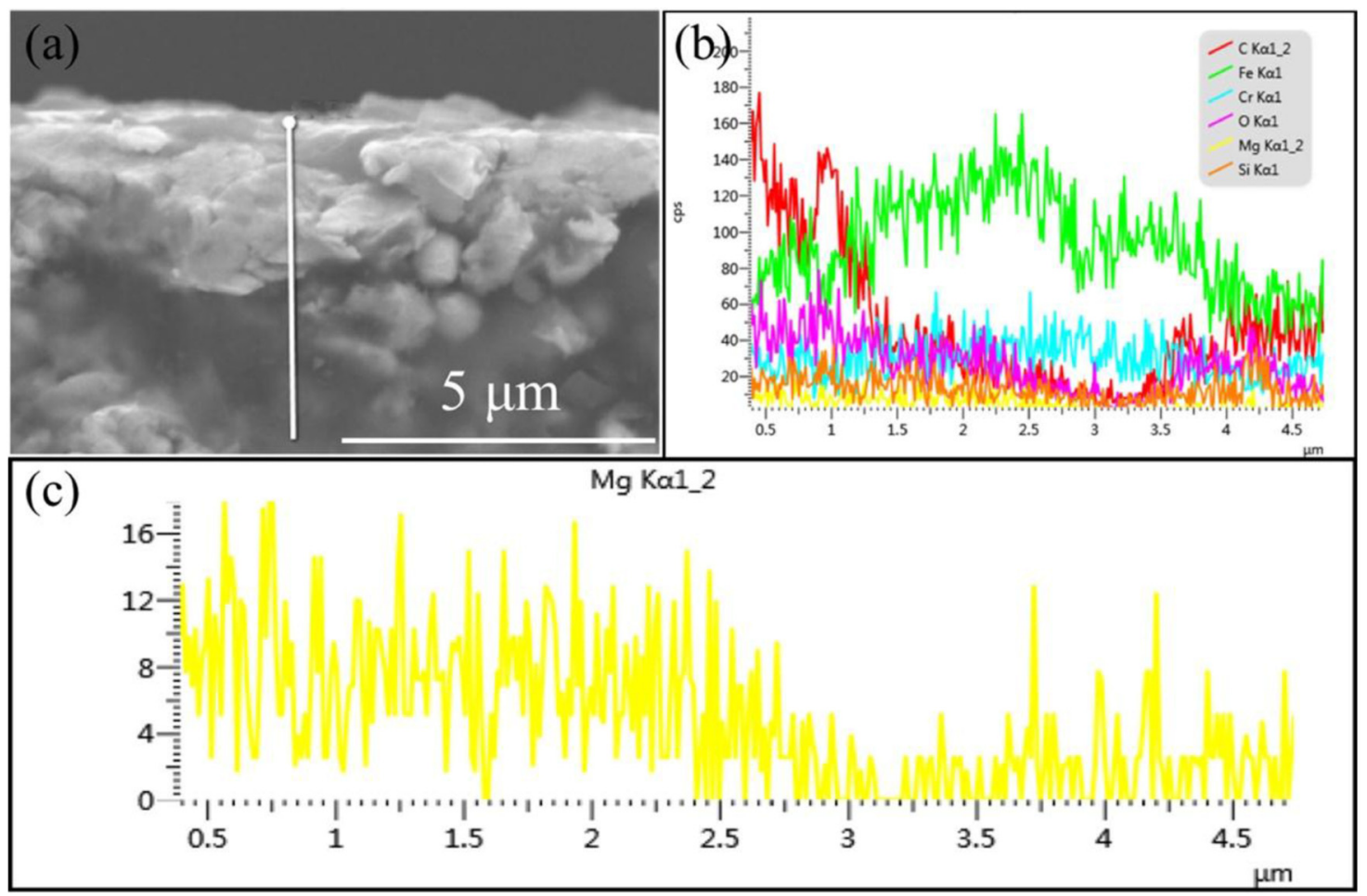

Fig. 10. Elements distribution from the layer to the substrate for vane A.
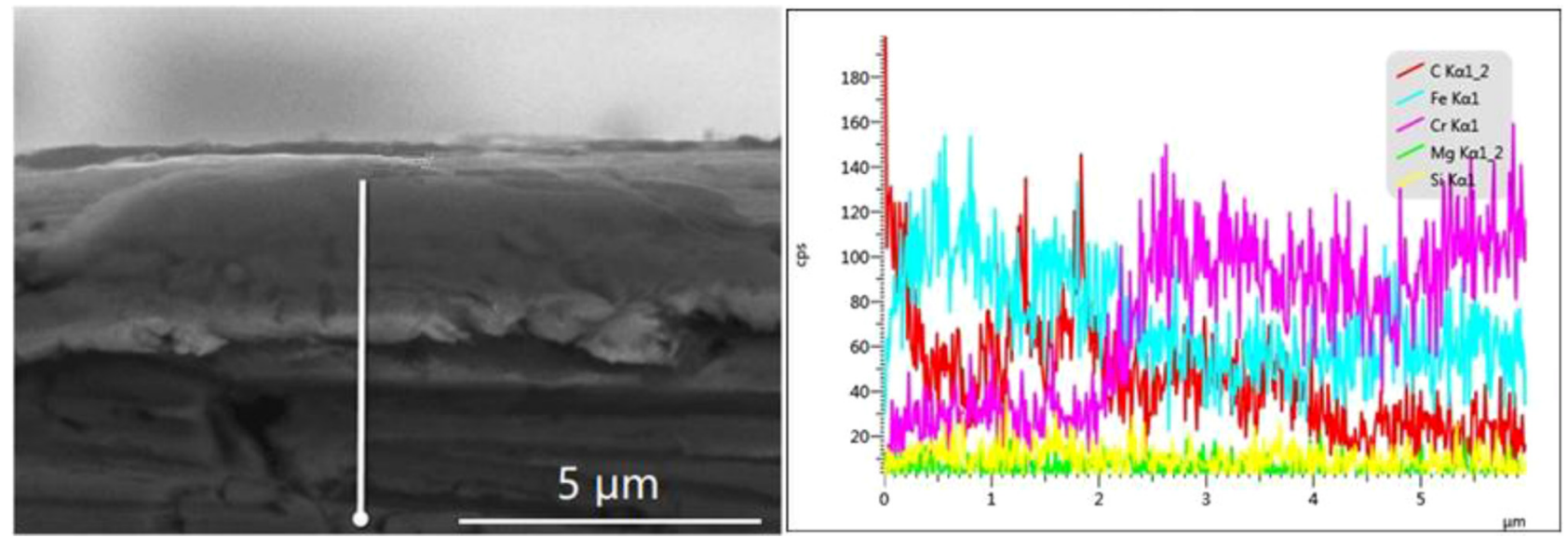

Fig. 11. Elements distribution from the layer to the substrate for vane B.

(a)

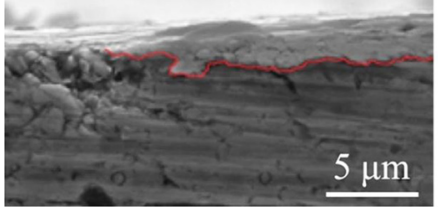

(b)

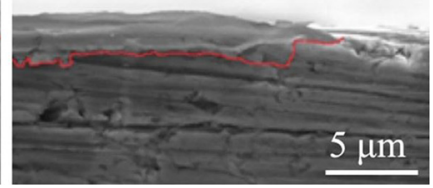

Fig. 12. SEM image of the worn surface: (a) left side of the worn surface, and (b) right side of the worn surface.

Comparison of the two curves shows that with lengthening time, the $\mathrm{C}$ element in the surface began to partly change from orderly carbon (SP2) to disordered carbon (SP3). This means that even although the substrate is not the friction surface, the pyrolysis of lubricating oil will deposit the $\mathrm{C}$ element on the surface due to the pressure brought by RA410 refrigerant and the oil. The Raman result proves that the self-repairing layer is an organic-inorganic composite layer, and the first thin-film of the layer is a carbon-enriched film due to the pyrolysis of lubricating oil. The other constructional constituents of the layer need further study.

Figure 13b shows the Raman results for the selfrepairing layers of vane $\mathrm{A}$ and $\mathrm{B}$. The peak corresponding to $692 \mathrm{~cm}^{-1}$ is $\mathrm{Fe}_{3} \mathrm{O}_{4} .1390 \mathrm{~cm}^{-1}$ (D-bond) and $1466 \mathrm{~cm}^{-1}$ are near the peak of diamond $\left(1332 \mathrm{~cm}^{-1}\right)$ and signifies an Sp3 bond. The peak of 1582 and $1588 \mathrm{~cm}^{-1}$ are near the $1580 \mathrm{~cm}^{-1}$ (G-bond), and signifies an Sp2 bond. The peak of $1881 \mathrm{~cm}^{-1}$ is not very clear. Therefore, it can be given no specific meaning. 

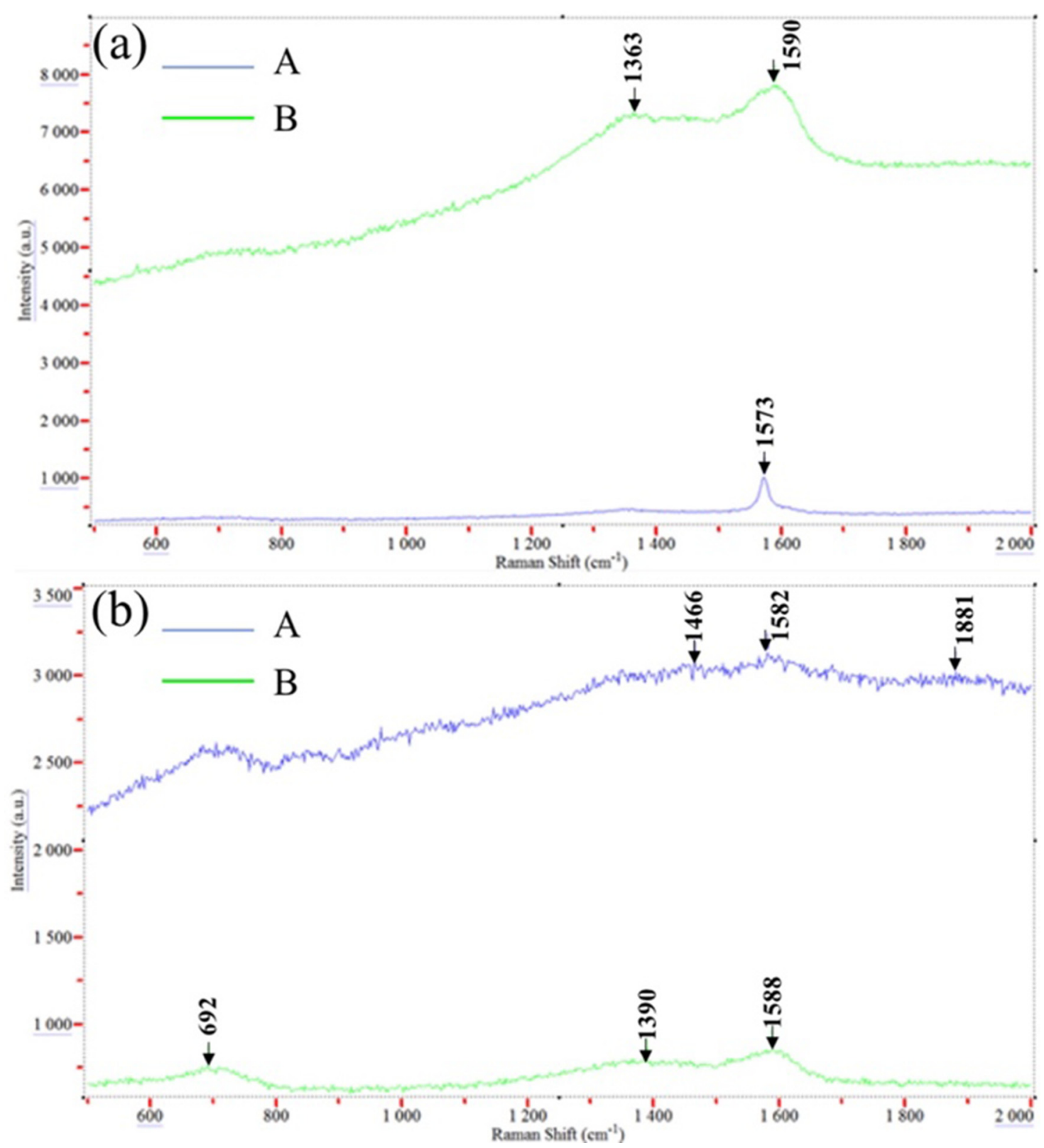

Fig. 13. Ramen spectrum of vane A and B, (a) is the substrate and (b) is self-repairing layers.

It is interesting to notice that there is no peak of $\mathrm{Fe}_{3} \mathrm{O}_{4}$ in vane $\mathrm{A}$ and also in vane $\mathrm{B}$. The reason for the generation of $\mathrm{Fe}_{3} \mathrm{O}_{4}$ is not very clear. It was surmised that the generation of $\mathrm{Fe}_{3} \mathrm{O}_{4}$ is due to high temperature internal oxidation produced by the phase change of the MSH [28] and further investigation would be needed in order to confirm it. Nevertheless, it is clear that the content of $\mathrm{Fe}_{3} \mathrm{O}_{4}$ increases with time. It is thought that, because the phase change of MSH is intensified with the time, more high-active oxygen is released, which takes part in the building of the self-repairing-layer. Possibly, the explanation that the formation of $\mathrm{Fe}_{3} \mathrm{O}_{4}$ is the result of the oxidation of highly reactive oxygen, could help to explain why $\mathrm{Fe}_{3} \mathrm{O}_{4}$ can be detected by Raman spectrometry, but it needs to be examined further.

\subsubsection{AFM analysis}

AFM analysis was used to present the micro-topography of the layers generated on the vane A and B. Figure 14 shows the micro-topography of the self-repairing layers for the worn surfaces of vane A and B respectively. Figure 15 shows the micro-roughness variation along the red lines in the two surfaces.

As can be seen in Figure 14a and b, there were many pits and humps in the worn surface of vane A, while Figure 14c and $d$ show the surface of vane B to be smooth with only a few pits. In addition, the RMS for vane A is $89 \mathrm{~nm}$, which is larger than that for the vane B $(65 \mathrm{~nm})$. Large humps appear in the surface of the vane A and the highest hump is $1267 \mathrm{~nm}$, while it is $194 \mathrm{~nm}$ only for vane B. This shows, for a longer working time, the self-repairing layer becomes 
(a)

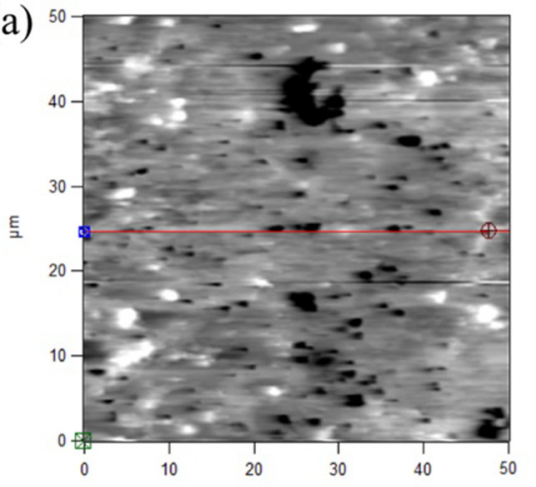

(c)

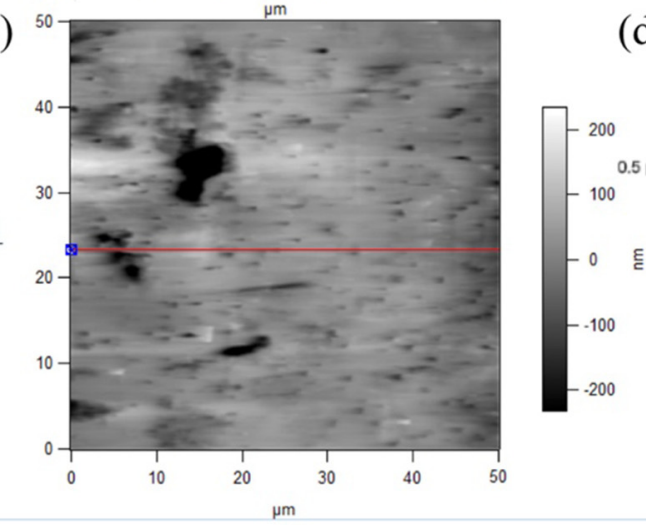

(b)

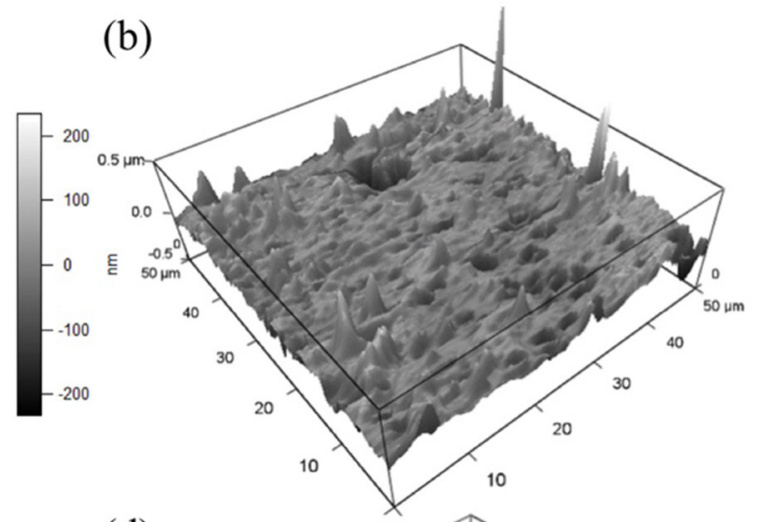

(d)

0
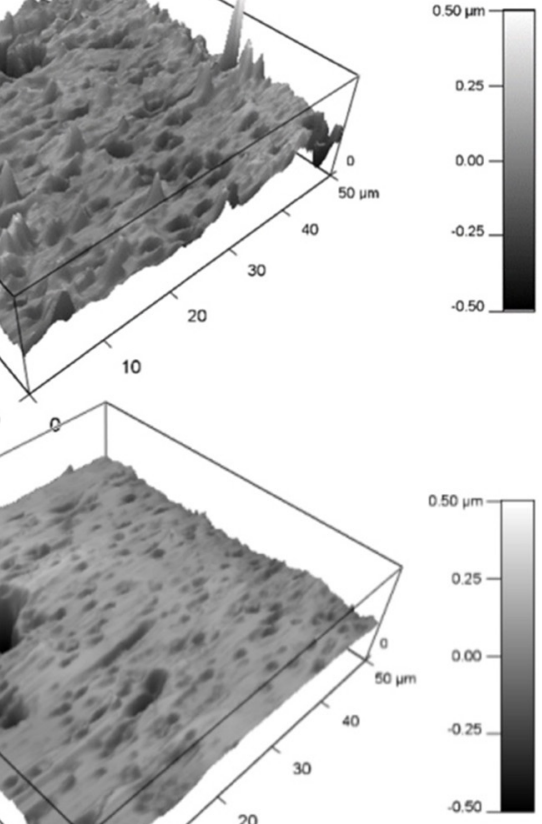

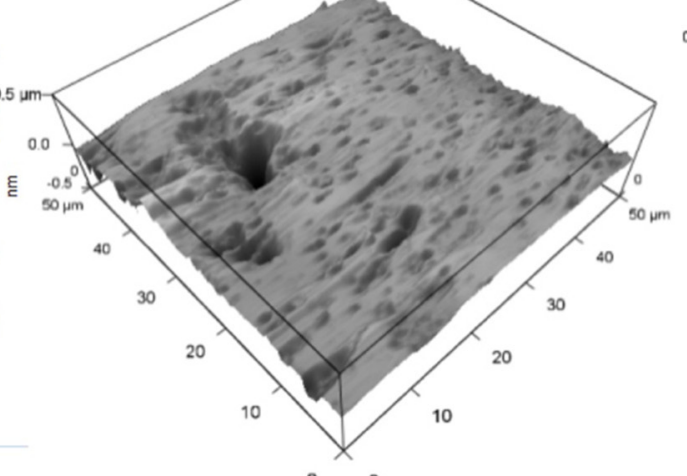

$0 \quad 0$

Fig. 14. AFM image of the worn surface layers: (a) and (b) are the worn surface of A, and (c) and (d) are the worn surface of B.

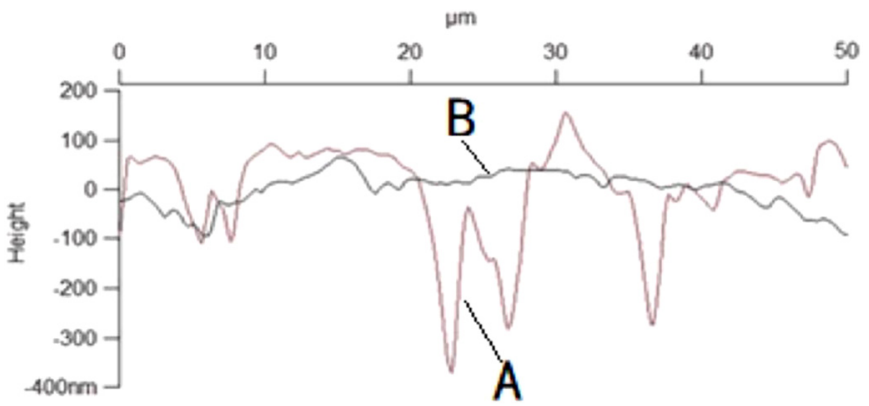

Fig. 15. Roughness variation for $\mathrm{A}$ and $\mathrm{B}$.

thicker and microscopically smoother, which is also confirmed by a comparison on the roughness shown in Figure 15.

To further determine the distribution of roughness along the affected surfaces, a detailed surface roughness analysis was carried out. Since generation of a self-repairing surface is, normally, localized, the layers are uneven, and the structure varies with location and time, surface roughness was measured and averaged on four different locations of the two vanes, each test length being $1.75 \mathrm{~mm}$. The results are shown in Table 3.

After $18 \mathrm{~h}$ working time for the vane $\mathrm{A}$ and $69 \mathrm{~h}$ for the vane $B$, the roughness of the worn surface was 0.083 and $0.07 \mu \mathrm{m}$ respectively for the vane $\mathrm{A}$ and $\mathrm{B}$, and the roughness of the substrate surface 0.105 and $0.110 \mu \mathrm{m}$, respectively. For the worn surface, although the microroughness of the self-repairing layer for the vane B (Fig. 15) could be smaller than that for the vane A, the overall surface roughness was not improved significantly. The result may help to explain why some previous research reported that in similar experiment, the coefficient of friction became even larger when MSH was added into the oil as an additive. It may also mean that in a boundary lubrication, localized generation of the self-repairing layers could result in an increase of the micro-roughness of the worn-surface and hence, increase of the coefficient of friction. It may also be deduced that the use of MSH nanorods as an additive of the lubricating oil could compensate for the wear, and at the same time, reducingfriction and reducing wear are two competing processes, until self-repairing layers cover sufficient area of the wear while their roughness is also reduced due to new wear, which could be achieved by sufficient length of working time of a friction pair.

\section{Conclusions}

The work described in this article was the first time that the MSH nanorods were used as an additive to the lubricant for compressor vanes. The test was done in simulated conditions relating to domestic air conditioning compressors. Vane/roller friction and wear phenomenon was 
Table 3. Surface roughness of vane A and B.

\begin{tabular}{|c|c|c|c|c|c|}
\hline $\begin{array}{l}\text { Roughness of worn surface } \\
\text { of vane } A(\mu \mathrm{m})\end{array}$ & $\mathrm{Ra}=0.060$ & $\mathrm{Ra}=0.095$ & $\mathrm{Ra}=0.079$ & $\mathrm{Ra}=0.097$ & Average $=0.083$ \\
\hline $\begin{array}{l}\text { Roughness of substrate } \\
\text { of vane } A(\mu \mathrm{m})\end{array}$ & $\mathrm{Ra}=0.117$ & $\mathrm{Ra}=0.098$ & $\mathrm{Ra}=0.109$ & $\mathrm{Ra}=0.096$ & Average $=0.105$ \\
\hline $\begin{array}{l}\text { Roughness of worn surface } \\
\text { of vane } B(\mu \mathrm{m})\end{array}$ & $\mathrm{Ra}=0.063$ & $\mathrm{Ra}=0.075$ & $\mathrm{Ra}=0.077$ & $\mathrm{Ra}=0.065$ & Average $=0.070$ \\
\hline $\begin{array}{l}\text { Roughness of substrate } \\
\text { of vane } B(\mu \mathrm{m})\end{array}$ & $\mathrm{Ra}=0.118$ & $\mathrm{Ra}=0.115$ & $\mathrm{Ra}=0.096$ & $\mathrm{Ra}=0.110$ & Average $=0.110$ \\
\hline
\end{tabular}

investigated and self-repairing-layer formation mechanism and structures were studied. The following conclusions may be drawn:

- With lengthening working time, the width of the worn surface of the compressor vanes tended to decrease, followed by the growth of self-repairing layers on the worn surface locally.

- With lengthening working time, the self-repairing layer became thicker. EDS showed that element distribution within the layers remained nearly unchanged, regardless of their different morphologies.

- Raman spectrometry showed that both, the substrate and the worn surface, have enriched carbon layers, and with lengthening working time, $\mathrm{C}$ gradually changes from orderly Carbon (SP2) to disorderly Carbon (SP3). This indicates that the layers generated on the friction surface are organic-inorganic composites. Their specific structure and generation of $\mathrm{Fe}_{3} \mathrm{O}_{4}$ need to be further studied.

- With lengthening time, micro-roughness of the layers reduces and surface of the grown layers become flatter. However, macro-roughness remains almost the same because self-repairing layers were generated locally on the rubbing surface.

The funding from the Natural Science Foundation of China (Grand numbers 51575369) to support the research reported in this paper is acknowledged. M. Wu acknowledges the support of Post-doctoral Research Foundation of Sichuan University (2018SCU12067).

\section{References}

1. B.S. Xu, Microstructure, mechanical properties and tribological behavior of tribofilm generated from natural serpentine mineral powders as lubricant additive, Wear 297 (2013) $802-810$

2. X.W. Qi, Characterization and auto-restoration mechanism of nanoscale serpentine powder as lubricating oil additive under high temperature, Tribol. Int. 44 (2011) 805-810

3. X.W. Qi, Tribological properties of serpentine nanoparticles as oil additive under different material friction pairs, Adv. Mat. Res. 199 (2011) 1051-1057

4. B.S. Zhang, B.S. Xu, Lanthanum Effect on the Tribological Behaviors of Natural Serpentine as Lubricant Additive, Tribol. Transac. 56 (2013) 417-427
5. B. Zhang, The effect of magnesium hydroxysilicate on the friction resistance of nodular cast iron and its self-repairing properties, J. Silicate 37 (2009) 40-50

6. Q.Y. Chang, The synthesis of magnesium silicate hydroxide with different morphologies and the comparison of their tribological properties, Tribol. Int. 119 (2018) 672-679

7. Y. Han, Synthesis of Chrysotile Used in Lubricant Additives, Bull. Chin. Ceram . Soc. 36 (2017) 3047-3052

8. Z.N. Jia, Y.L. Yang, J.J. Chen, Influence of serpentine content on tribological behaviors of PTFE/serpentine composite under dry sliding condition, Wear 268 (2010) 996-1001

9. G.Z. Zhu, Antiwear and Self-repairing Mechanisms of Magnesium Hydroxysilicate Composite Powder as a Lubricating Oil Additive for Steel-Steel Pair, Tribology 32 (2012) $183-188$

10. H. Yang, Study on Tribological Behavior of $\mathrm{Mg}_{6} \mathrm{Si}_{4} \mathrm{O}_{10}(\mathrm{OH}) 8$ Additive Package with Steel Tribo-Pair, Tribology 25 (2005) 308-311

11. L. Qing, The research progress of hydroxysilicate as a selfrepairing lubricant additive, Bull. Chinese Ceram. Soc. 30 (2011) 840-844

12. Y. Z. Lee, Friction and wear of the rotary compressor vanevane surfaces for several sliding conditions, Wear 255 (2003) $1168-1173$

13. S.L. Huang, Performance analysis on restoration layer of metallic surface induced by machinery, China Surf. Eng. 29 (2016) 6-16

14. J. Wen, Friction and wear behavior of rotor compressor and anti-friction technology, Home Appliance Technol. 09 (2009) $62-64$

15. F. Tian, Simulation analysis of friction power and sliding plate of vane compressor, Fluid Mach. 09 (2005) 14-16

16. H.X. He, Analysis and test of pressure and power of vane air compressor, J. Mech. Eng. 04 (2006) 76-81

17. Y. Gang, Study on radial clearance leakage of rotor in rolling rotor compressor, Fluid Mach. 09 (2005) 72-75

18. C.X. Long, Application of DLC film vane in rotary compressor, [A] Academic annual meeting of China institute of refrigeration, 2011

19. X. Chen, The surface treatment for the vane in R410A air compressor, Shanghai Jiaotong University, 2008, 20-25

20. Z. Li, The application of wear-resisting self-lubricating DLC coating on air source heat pump water heater compressor, Refrig. Air-Condition. 15 (2015) 58-60

21. Z. Haiyan, Study on the preparation and absorption properties of magnesium hydroxysilicate nanorods, J. Synth. Cryst. 44 (2015) 2908-2911 
22. F. Gao, In situ surface modification and secondary surface modification of magnesium hydroxysilicate, China Surf. Eng. 23 (2010) 82-85

23. H.L. Mei, Nano-hydroxysilicate was prepared by anti-phase microemulsion, Mater. Rev. 26 (2012) 86-88

24. M. Wen, Preparation and characterization of magnesium hydroxysilicate micropowder, Mater. Rev. 24 (2010) 135-138

25. J.Y. Yun, The frictional properties of synthetic serpentine, J. Anshan 38 (2015) 18-21
26. Z. Fuyan, Preparation and friction properties of serpentine /La composite powder, J. Chinese Ceram. Soc. 40 (2012) $126-130$

27. Y. Xu, Thermodynamics and tribological properties of lanthanum/serpentine composite lubricating materials, Sci. Eng. Powder Metall. Mater. 16 (2011) 349-354

28. Y.S. Jin, The oxidation effect of serpentine in the iron fund is the effect of the self-healing layer of the wear surface, China Surf. Eng. 23 (2010) 23-33

Cite this article as: Libo Wang, Yi Yang, Yi Qin, Gang Yang, Yuan Qin, Mingxia Wu, Self-repairing mechanism and surface characterization of compressor vanes lubricated with oil added with magnesium silicate hydroxide nanorods, Manufacturing Rev. 6, $26(2019)$ 